\title{
IMMUNOHISTOCHEMICAL LOCALIZATION OF VITAMIN B12 R-BINDER IN UTERINE CERVICAL AND ENDOMETRIAL ADENOCARCINOMAS
}

\author{
Young-Chi KIM ${ }^{1}$, Katsuhiko OGAWA ${ }^{2}$, Yoshio WAKATSUKI ${ }^{3}$, \\ YASUAKI NAKASHIMA ${ }^{4}$, KOSHO TAKASU ${ }^{1}$ AND \\ HIROHIKO YAMABE ${ }^{5}$ \\ Department of Clinical Laboratory Medicine ${ }^{1}$, Kyoto City Hospital, Kyoto 604, Department of Internal \\ Medicine $^{2}$, Biwako-Gakuen Hospital, Shiga, Department of Geriatric Medicine ${ }^{3}$, Kyoto, \\ Laboratory of Central Clinical Laboratory ${ }^{4}$, Laboratory of Anatomic \\ Pathology ${ }^{5}$, Kyoto University Hospital, Kyoto 606
}

Received for publication July 1, 1993 and in revised form August 2, 1993

\begin{abstract}
Vitamin B12 R-binder (R-binder), a binding protein for cobalamin, is distributed preferentially in the normal endocervical epithelium. Endometrial epithelium is virtually negative for R-binder. The $\mathbf{R}$ binder expression in the uterine cervical and endometrial adenocarcinomas has not been reported. We investigated the immunohistochemical localization of R-binder in surgically resected cervical adenocarcinomas (CAs) and endometrial adenocarcinomas (EAs). Immunoreactivity was graded semiquantitatively. Seventeen of $20(85 \%)$ CAs and 22 of 31 (71\%) EAs showed R-binder immunoreactivity. Eight of 11 (73\%) well-differentiated CAs and 8 of $23(35 \%)$ well-differentiated EAs were strongly positive for R-binder $(P<0.05)$. Immunoreactivity was seen in the membrane, cytoplasm and secretions of the tumor cells. Secretions in the well-differentiated CAs $(9 / 10,90 \%)$ were stained more frequently than those in welldifferentiated EAs $(8 / 17,47 \%)(P<0.05)$.

R-binder positivity may be more useful in the diagnosis of well-differentiated CAs than of well-differentiated EAs.
\end{abstract}

Vitamin B12 R-binder (R-binder), one of the specific binding proteins for cobalamin $(1,7)$, is a family of immunologically related glycoproteins. Rbinder is found in various body fluids, granulocytes and plasma $(1,7)$. It is also distributed in the glandular epithelium of various human tissues such as the digestive tract, bronchial gland, renal proximal tubule, sweat gland, mammary gland, prostate, and female genital tract $(1,7,11-14)$.

We have previously reported the immunohistochemical localization of R-binder in the normal uterine tissues (11). In all the cervices examined, $R$ binder localization was found in the surface and glandular epithelium. R-binder was observed both at the apical portion of the epithelium and in the cytoplasm of the endocervical columnar epitheliual cells. On the

Correspondence to: Young-Chi Kim, Department of Clinical Laboratory Medicine, Kyoto City Hospital, 1-2 Higashi Takadacho, Mibu, Nakakyo-ku, Kyoto 604, Japan. other hand, endometrial glandular epithelium was consistently negative for R-binder (11).

$\mathrm{R}$-binder expression has been detected in various tumors of the digestive tract (15), urinary tract (17), lung (19), salivary gland (20), and breast (18). However, its expression in uterine adenocarcinomas has not yet been investigated. Because of the preferential localization of R-binder in the cervical epithelium, it is of interest to determine whether there is any difference in R-binder expression between the cervical (CAs) and endometrial adenocarcinomas (EAs). In the present study, we investigated R-binder localization in CAs and EAs using immunohistochemical methods.

\section{MATERIALS AND METHODS}

Cases

From the surgical pathology file of Kyoto University Hospital, 20 cases of CAs and 31 cases of 
EAs were randomly selected. All the patients had undergone abdominal hysterectomy with salpingooophorectomy. The origin of the tumors was confirmed by gross examination. Equivocal cases were not included in our investigation. The removed specimens were fixed in $10 \%$ formalin and embedded in paraffin. The tumors were classified according to the WHO classification (21). Histologically, all the CAs were of the endocervical type and all the EAs were of the endonetrial type. Of the $20 \mathrm{CAs}, 11,5$, and 4 were well-, moderately-, and poorly-differentiated adenocarcinomas, respectively. In the 31 cases of EAs, 23, 6, and 2 cases were classified as well-, moderately-, and poorly-differentiated adenocarcinomas, respectively (Table 1 ). Freshly cut $4-\mu \mathrm{m}$ thick sections were used for immunohistochemical staining.

\section{Monoclonal antibody}

Purification of vitamin B12 R-binder from human saliva, preparation of mouse monoclonal antibody 55-D, and its specificity were previously described in detail elsewhere (27). In brief, monoclonal antibody $55-\mathrm{D}$ was prepared by immunizing balb/c mice with affinity purified saliva $\mathrm{R}$-binder. Hybridization was performed according to the modified method of Herzenberg and Milstein (10).

Immunoperoxidase technique

Immunohistochemistry was carried out using the avidin-biotin peroxidase complex (ABC) method
(12). In brief, the sections were pretreated with $0.5 \%$ protease type 24 (Sigma Chem., USA). After blocking endogenous peroxidase activity, the sections were coated with $5 \%$ normal goat serum, and were incubated overnight with antibody 55-D at a dilution of $1: 500$ at $4^{\circ} \mathrm{C}$. Then, the sections were reacted with biotinylated goat anti-mouse IgG (Vector Labs, USA) diluted at 1:500 and processed using an ABC kit (Vectastain, Vector Labs, USA). Finally, color was developed by the peroxidase reaction method with $3,3^{\prime}$-diaminobenzidine $(0.05 \% \mathrm{w} / \mathrm{v})$ and hydrogen peroxide $(0.01 \%)$ in $0.05 \mathrm{M}$ Tris $\mathrm{HCl}$ buffer, $\mathrm{pH}$ 7.6. The sections were counterstained with methylgreen. The negative control was obtained with replacement of the specific antibody with the culture supernatant of a mouse myeloma cell line used for hybridization. Normal cervical tissues from myomabearing uteri served as positive controls.

The immunoreactivity was evaluated semiquantitatively as follows:

$(H)$, strongly positive: more than one half of the tumor cells were stained (Figs. 1, 2);

$(+)$, positive: less than one half of the tumor cells were stained;

$(-)$, negative: no tumor cell was stained.

Statistical analysis

The chi-squared test was used for the statistical analysis and $P<0.05$ was regarded as significant.

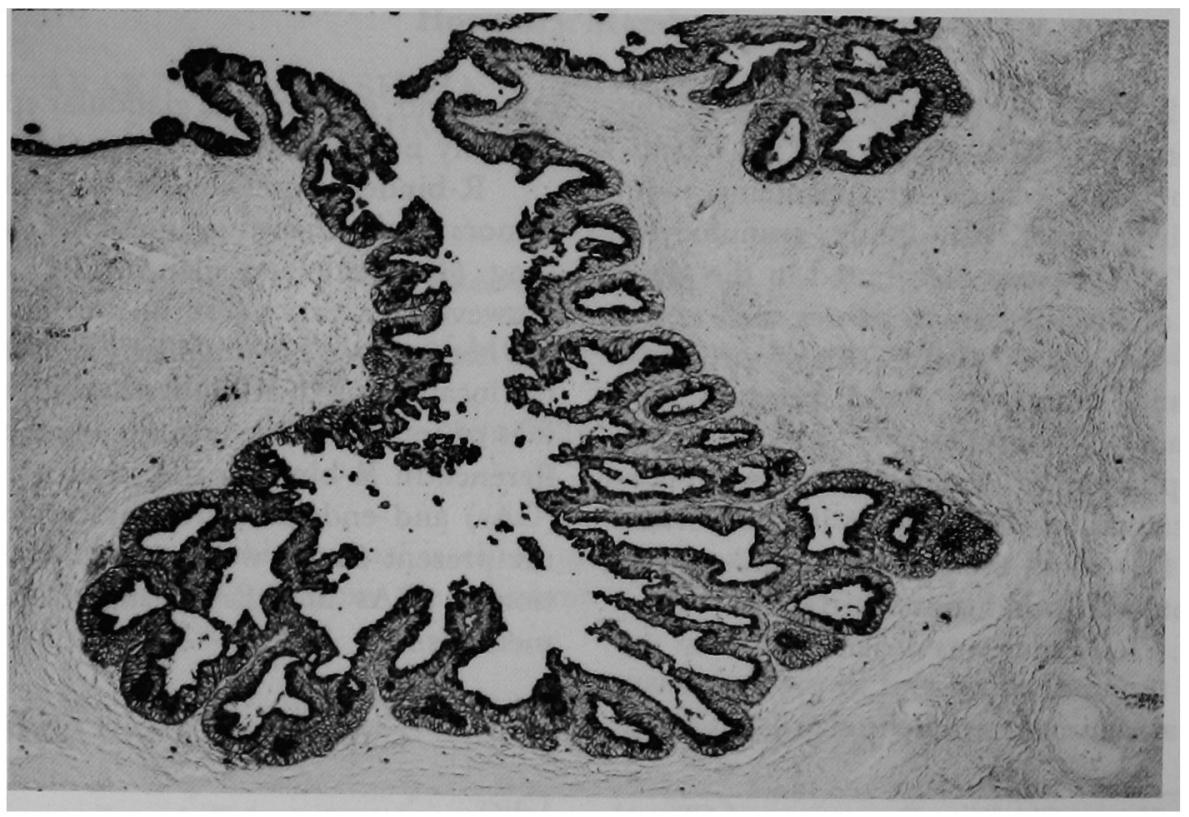

FIg. 1. Well-differentiated cervical adenocarcinoma. Almost all the tumor cells are stained for R-binder. Immunoperoxidase. 


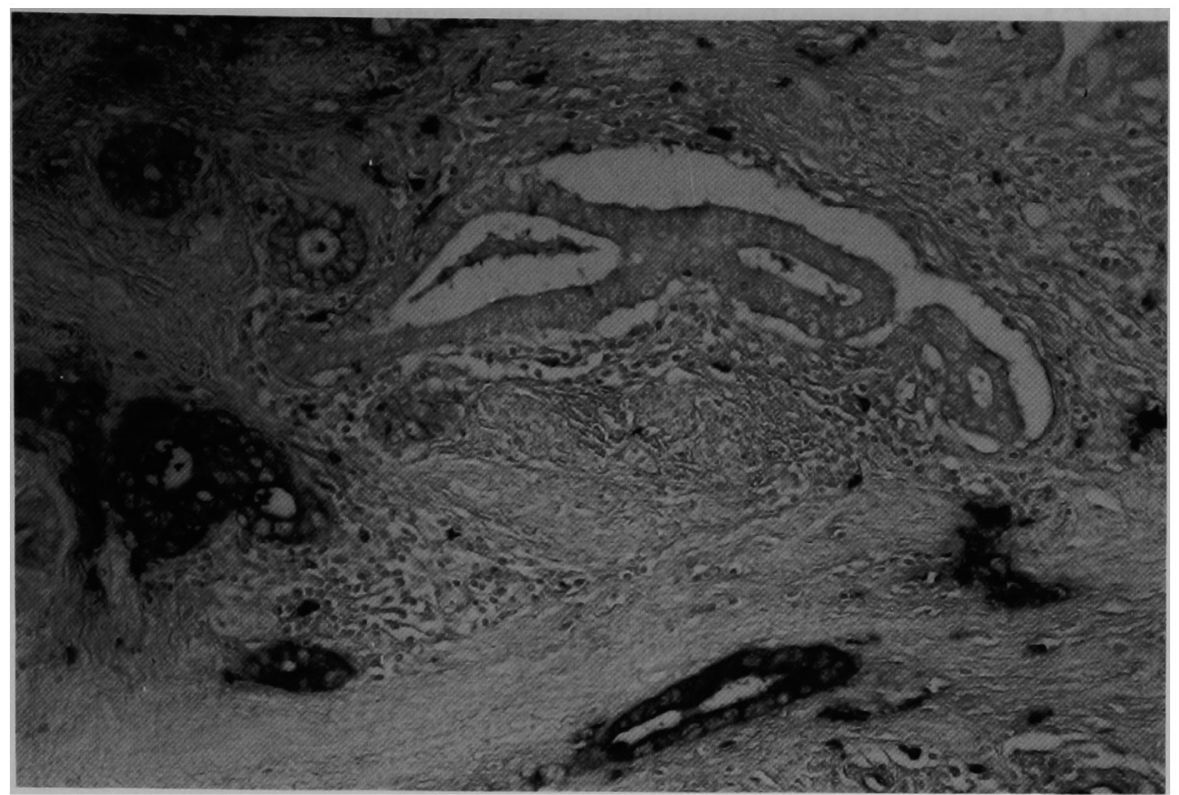

Fig. 2. Well-differentiated cervical adenocarcinoma. About one half of the tumor cells are positive for R-binder. Immunoperoxidase. $\times 170$

TABLE 1. Degree of $R$-binder immunoreactivity in 20 cervical and 31 endometrial adenocarcinomas

\begin{tabular}{cclc}
\hline DIFFERENTIATION & DEGREE & CERVICAL & ENDOMETRIAL \\
\hline WELL & $(+)$ & $8 / 11(73 \%)^{*}$ & $8 / 23(35 \%)^{*}$ \\
& $(+)$ & $2 / 11$ & $2 / 23$ \\
MODERATE & $(-)$ & $1 / 11(9.1 \%)$ & $8 / 23(35 \%)$ \\
& $(+)$ & $3 / 5$ & $4 / 6$ \\
POOR & $(+)$ & $1 / 5$ & $2 / 6$ \\
& $(-)$ & $1 / 5$ & $0 / 6$ \\
& $(+)$ & $1 / 4$ & $0 / 2$ \\
& $(+)$ & $2 / 4$ & $1 / 2$ \\
& $(-)$ & $1 / 4$ & $1 / 2$ \\
\hline \multirow{2}{*}{ TOTAL } & $(+)$ & $12 / 20$ & $10 / 31$ \\
& $(+)$ & $5 / 20$ & $9 / 31$ \\
\hline
\end{tabular}

$(+)$ : more than one half of the tumor cells were stained;

$(+)$ : less than one half of the tumor cells were stained;

$(-)$ : no tumor cell was stained.

* $\mathrm{P}<0.05$.

\section{RESULTS}

The degree of R-binder immunoreactivity in CAs and EAs is summarized in Table 1 . Immunoreactivity was found in 17 of $20(85 \%)$ CAs and in 22 of 31 (71\%) EAs. Of these positive cases, well-differentiated CAs ( $8 / 11$ cases, $73 \%$ ) were strongly positive for
R-binder more frequently than well-differentiated EAs $(8 / 23$ cases, $35 \%, P<0.05)$. Only one of 11 well-differentiated CAs (9.1\%) was negative for R-binder, while 8 of 23 well-differentiated EAs (35\%) were. As for the moderately-and poorly-differentiated tumors, there was no significant difference in the number of strongly positive cases between CAs and EAs. The 
more differentiated the CAs were, the more frequently they were strongly positive for R-binder. Among the EAs, 8 of 23 well-differentiated EAs were strongly positive whereas none of the poorly-differentiated EAs were. However, the small number of cases studied precluded us from statistical analysis of the relation between the differentiation and the degree of $\mathbf{R}$-binder im- munoreactivity.

R-binder localization is summarized in Table 2. In both types of tumors, R-binder immunoreactivity was detected along the surface membrane (Figs. 3, 4), in the cytoplasm of tumor cells (Figs. 3-6), and in the secretory products within the neoplastic glands (Figs. $5,6)$. Cytoplasmic staining was observed in the sup-

TABLE 2. Localization of $R$-binder in 20 cervical and 31 endometrial adenocarcinomas

\begin{tabular}{cccc}
\hline DIFFERENTIATION & LOCALIZATION & CERVICAL & ENDOMETRIAL \\
\hline \multirow{2}{*}{ WELL } & MEM & $10 / 11$ & $14 / 23$ \\
& CYTO & $8 / 11$ & $11 / 23$ \\
& SEC & $9 / 10(90 \%)^{*}$ & $8 / 17(47 \%)^{*}$ \\
MODERATE & MEM & $4 / 5$ & $6 / 6$ \\
& CYTO & $3 / 5$ & $5 / 6$ \\
& SEC & $4 / 5$ & $3 / 4$ \\
POOR & MEM & $2 / 4$ & $1 / 2$ \\
& CYTO & $3 / 4$ & $1 / 2$ \\
& SEC & $1 / 2$ & $1 / 1$ \\
\hline \multirow{2}{*}{ TOTAL } & MEM & $16 / 20$ & $21 / 31$ \\
& CYTO & $14 / 20$ & $17 / 31$ \\
& SEC & $14 / 17$ & $12 / 22$ \\
\hline
\end{tabular}

MEM: membranous staining;

CYTO: cytoplasmic staining;

SEC: staining in the secretory product.

* $\mathrm{P}<0.05$.

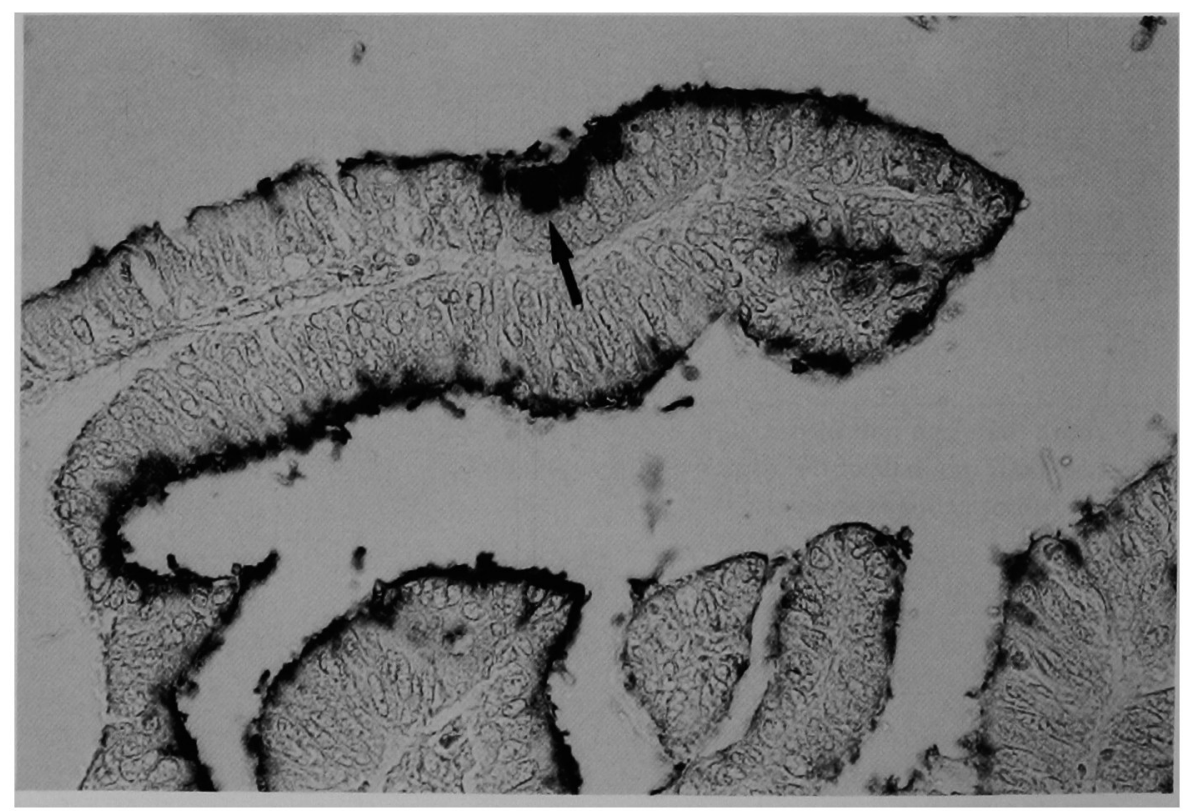

Fig. 3. Well-differentiated cervical adenocarcinoma. Immunostaining is seen mainly along the surface membrane. A few tumor cells show supranuclear cytoplasmic staining. Arrow, immunoperoxidase stain. $\times 340$ 


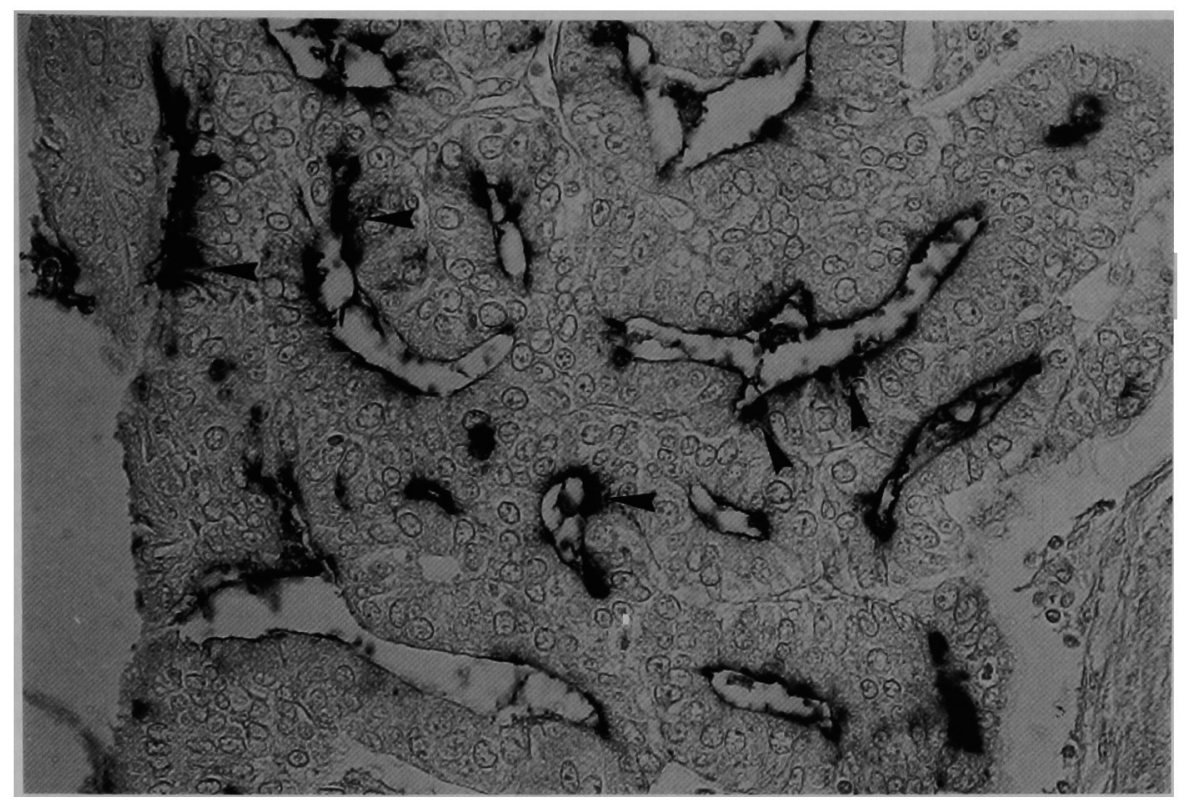

FIG. 4. Well-differentiated endometrial adenocarcinoma. Immunostaining is seen mainly along the surface membrane. Several tumor cells exhibit supranuclear cytoplasmic reactivity. Arrowheads, immunoperoxidase. $\times 340$

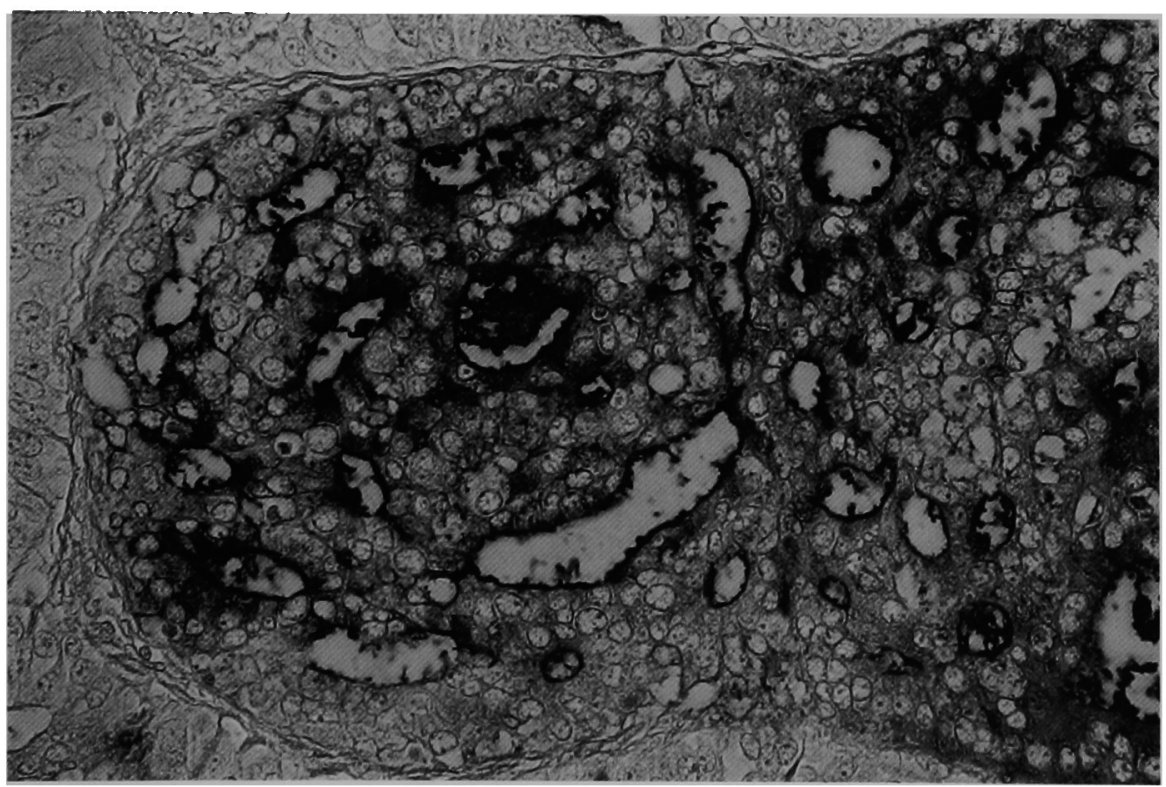

Fig. 5. Moderately-differentiated endometrial adenocarcinoma. Almost all the tumor cells show positive reactivity, with immunostaining being seen along the surface membranes and in the cytoplasm. Cytoplasmic staining is found in the supranuclear portion or is diffusely distributed. Secretory products in the neoplasmic glands are positively stained. Immunoperoxidase. $\times 340$

ranuclear portion (Figs. 3, 4) or was diffusely distributed (Figs. 5, 6). Secretory products of well-differentiated CAs (9/10 cases, $90 \%)$ reacted more frequently than those of well-differentiated EAs (8/17 cases, $47 \%$, $\mathrm{p}>0.05)$. However, there was no significant difference in R-binder distribution between CAs and EAs as a whole. In both types of tumors, R-binder distribution was not correlated with tumor differentia- 


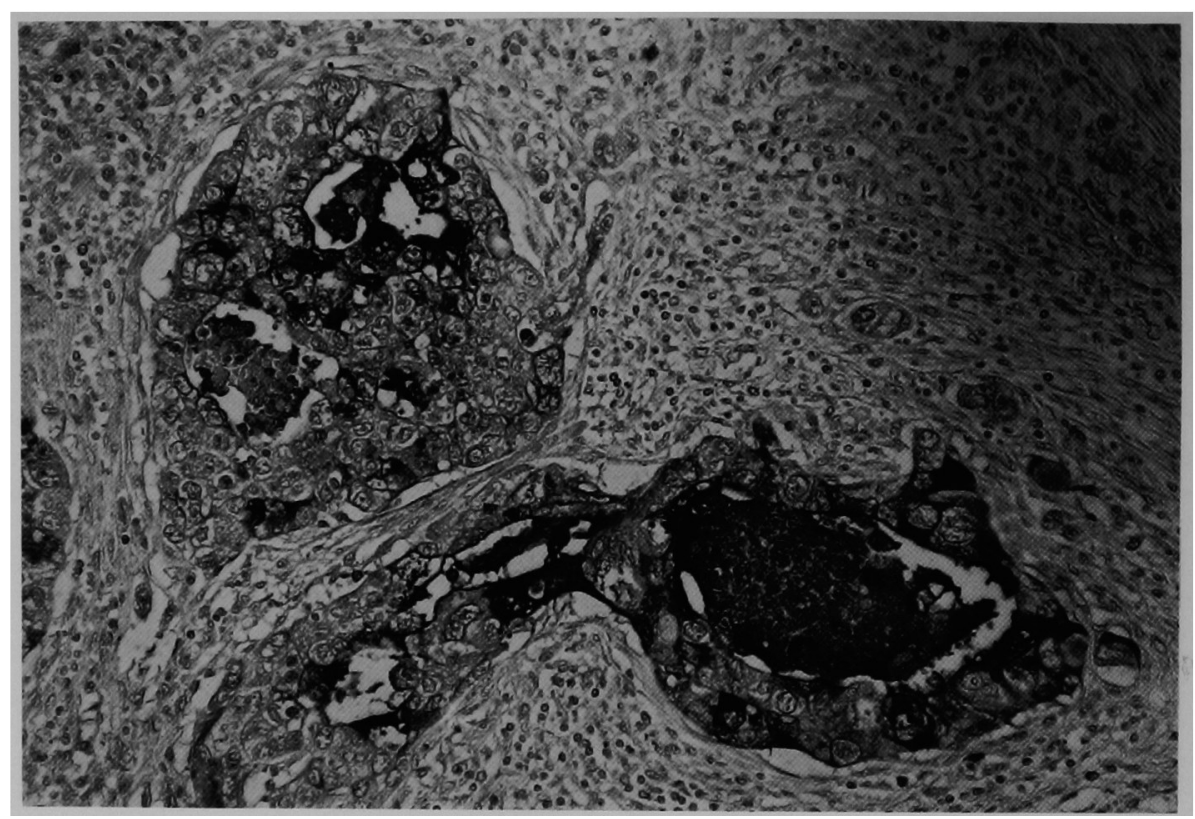

Fig. 6. Moderately-differentiated cervical adenocarcinoma. Tumor cells exhibited diffuse cytoplasmic staining. Secretory products in the malignant glands are intensely stained for R-binder. Immunoperoxidase. $\quad \times 170$

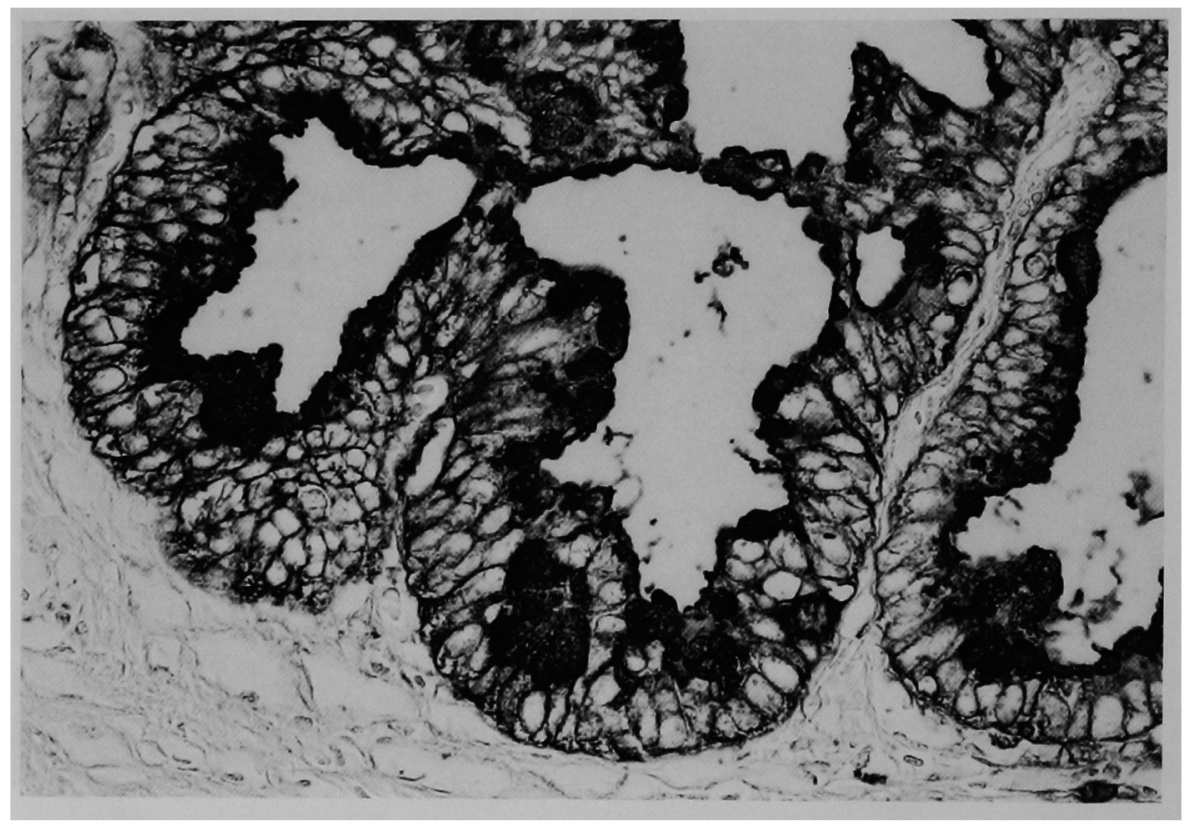

FIG. 7. The same case as in Fig. 1 of well-differentiated cervical adenocarcinoma. Intense supranuclear cytoplasmic staining with discrete globular shape is observed. Immunoperoxidase. $\times 340$

tion.

Three well-differentiated CAs showed intense supranuclear cytoplasmic staining with a distinct globular shape (Fig. 7). In the EAs, supranuclear cytoplasmic staining did not take the form of a discrete globular shape as in the CAs (Fig. 5).

\section{DISCUSSION}

The present study demonstrated R-binder im- 
munoreactivity both in the CAs and EAs. In addition, a substantial proportion of the EAs showed cytoplasmic staining that was not seen in the normal endometrial epithelium (11).

The presence of R-binder immunoreactivity in the EAs is not unexpected. Kudo et al. reported that normal gastric mucosa was negative for $\mathrm{R}$-binder (14), whereas 38 of $47(81 \%)$ gastric carcinomas showed $R$ binder positivity (15). Such a difference in the Rbinder staining pattern between normal and neoplastic tissues was also demonstrated in the breast (18). In the normal breast tissues, R-binder was observed on the luminal surface of ducts. Benign tumors such as fibroadenomas showed positive staining in the apical portion of the epithelial components, while some intraductal and invasive carcinomas revealed diffuse cytoplasmic staining (18).

Immunoreactivity of R-binder is intense in mucous cells of various organs, such as the salivary gland (20), colon (14), lung (19), uterus (11), and in the intestinal metaplastic mucosa of the stomach (14). Therefore, $\mathbf{R}$-binder may be related to mucous material. In fact, mucosubstances are well demonstrated in most of the EAs $(5,22,24)$.

In the present study, well-differentiated CAs were strongly positive for R-binder more frequently than were the well-differentiated EAs. We also found that the secretory products in the well-differentiated CAs were positive for $\mathbf{R}$-binder more frequently than those in the well-differentiated EAs. We speculate that well-differentiated CAs retained the phenotype of the parental tissues compared with EAs and thereby caused this difference. This assumption is supported by the fact that the supranuclear globular cytoplasmic immunostaining seen in the well-differentiated CAs is similar to the staining pattern observed in the normal tissues (11). The difference in immunoreactivity of the secretory products may be a reflection of the higher. degree of positivity in well-differentiated CAs than that in well-differentiated EAs. In general, CAs are reported to produce mucosubstances in a higher proportion than do EAs $(5,24)$.

Distinguishing cervical adenocarcinomas (CAs) from endometrial adenocarcinomas (EAs) is often difficult in cases affected by advanced tumors. Several investigators reported that immunoreactivity for CEA $(5,26)$ or vimentin $(6)$, lectin histochemistry $(25,30)$, and mucin distribution and composition $(22,24)$ are of some use in the differential diagnosis. The finding of $R$-binder immunoreactivity in more than one half of the tumor cells indicates well-differentiated CA rather than well-differentiated EA. On the other hand, negative staining for R-binder in well-differentiated uterine adenocarcinoma suggests EA.

Increased concentrations of serum $\mathbf{R}$-binder are reported in patients with various tumors such as breast carcinoma $(4,8)$, hepatocellular carcinoma $(2,29)$, gastric adenocarcinoma $(3,4)$, colon adenocarcinoma $(3,4)$, pancreatic adenocarcinoma (4), and renal cell carcinoma (4). Carmel and Eisenberg reported that $6 \%$ of 139 patients with non-hematologic malignancy showed increased serum content of R-binder (4). Sheppared et al. found that tumor tissue of disseminated analplastic carcinoma contained a considerably higher concentration of R-binder and they speculated that the tumor tissue was the source of this increased concentration (23). In contrast, Wahlstedt and Gräsbeck speculated that urinary $\mathrm{R}$-binder originates from leukocytes (28). However, no leukocytic infiltration was seen in the adenocarcinomas investigated in the present study. In addition, the immunoreactivity found in the tumor cells and secretions suggests that production of $\mathbf{R}$-binder in the tumor cells. These findings support the view of Sheppard et al. (23).

$\mathrm{R}$-binder in milk and intestines is considered to suppress bacterial growth by inhibiting bacterial uptake of cobalamin $(1,7,9,16)$. In addition, $R$-binder may bind unnecessary cobalamin analogues or excessive cobalamin for either storage or excretion into bile (7). To elucidate the physiological significance of $\mathbf{R}$ binder in normal and neoplastic tissues, further studies are needed.

\section{ACKNOWLEDGMENT}

The authors thank Dr. K. Takakura, Department of Obsterics and Gynecology, Kyoto University Hospital for pertinent comments.

\section{REFERENCES}

1. Allen, R. H.: Human vitamin B12 transport proteins. Progress in Hematology 9; 57-84, 1975.

2. Burger, R. L., Waxman, S., Gilbert, H. S., Mehlman, C. S. and Allen, R. H.: Isolation and characterization of a novel vitamin B12 binding protein associated with hepatocellular carcinoma. J. Clin. Invest. 56; 1262-1270, 1975.

3. Carmel, R.: Extreme elevation of serum transcobalamin I in patients with metastatic cancer. N. Engl. J. Med. 292; 282-284, 1975.

4. Carmel, R. and Eisenberg, L.: Serum vitamin B12 and transcobalamin abnormalities in patients with cancer. Cancer 40; 1348-1353, 1977.

5. Cohen, C., Shulman, G. and Budgeon, L. R.: Endocer- 
vical and endometrial adenocarcinoma: an immunoperoxidase and histochemical study. Am. J. Surg. Pathol. 6; 151-157, 1982.

6. Dabbs, D. J., Geisinger, K. R. and Norris, H. T.: Intermediate filaments in endometrial and endocervical carcinomas: the diagnostic utility of vimentin patterns. Am. J. Surg. Pathol. 10; 568-576, 1986.

7. Donaldon, R. M.: Intrinsic factor and transport of cobalamin. "In Physiology of the gastrointestinal tract." Raven, New York, 1981, pp. 641-658.

8. Gimsing, P. and Hippe, E.: Increased concentration of transcobalamin $I$ in a patient with metastatic carcinoma of the breast. Scand. J. Hacmatol. 21; 243-249, 1978.

9. Gullberg, R.: Possible antimicrobial function of the large molecular size vitamin B12 binding protein. Scand. J. Gastroenterol. 9 (suppl); 19-21, 1974.

10. Herzenberg, L. A. and Milstein, C.: Cell hybrids of myelomas with antibody forming cells and $\mathrm{T}$ lymphocytes with $T$ cells. In "Handbook of Experimental Immunology", Blackwell Scientific Publications, Oxford, 1978, pp. 25.1-25.7.

11. Kim, Y. C., Kudo, H., Ogawa, K., Ohshio, G., Aye, T. T., Nakashima, Y., Takakura, K., Fujii, S., Inada, M. and Yamabe, H.: Vitamin B12 R-binder localization in the human uterus: an immunohistochemical study. Am. J. Obstet. Gynecol. 159; 522-526, 1988.

12. Kim, Y. C., Wakatsuki, Y., Ogawa, K., Nakashima, Y., Takasu, K. and Yamabe, H.: Immunohistochemical localization of vitamin B12 R-binder in the human fallopian tube. Acta Histochem. Cytochem. 23; 237-244, 1990.

13. Kudo, H., Oshio, G., Ogawa, K., Wakatsuki, Y., Inada, M., Hamashima, Y. and Miyake, T.: Distribution of vitamin B12 $\mathrm{R}$ binder in normal human tissues: an immunohistochemical study. J. Histochem. Cytochem. 35; 855-859, 1987.

14. Kudo, H., Inada, M., Oshio, G., Wakatsuki, Y., Ogawa, K., Hamashima, Y. and Miyake, T.: Immunohistochemical localization of vitamin B12 R-binder in the human digestive tract. Gut 28; 339-345, 1987.

15. Kudo, H., Oshio, G., Ogawa, K., Kim, Y. C., Wakatsuki, Y., Nakashima, Y., Yamabe, H. and Inada, M.: Distribution of vitamin B12 R-binder in carcinomas of the digestive tract. J. Clin. Pathol. 41; 320-323, 1988.

16. Marcoullis, G., Nicolas, J. P., Parmentier, Y., Jimenez, M. and Gerard, P.: A derivative of R-type cyanocobalamin binding proteins in the human intestine: candidate antibacterial molecule. Biochim. Biophys. Acta 633; 289-294, 1980.

17. Ogawa, K., Kudo, H., Kim, Y. C., Nakashima, Y., Ohshio, G., Yamabe, H., Inada, M. and Hamashima, Y.: Immunohistochemical distribution of vitamin B12 $\mathrm{R}$-binder in renal cell carcinoma. Virchows Arch $A$ 412; 23-26, 1987.

18. Ogawa, K., Kudo, H., Kim, Y. C., Nakashima, Y.,
Ohshio, G. and Yamabe, H.: Expression of vitamin B12 R-binder in breast tumors. Arch. Pathol. Lab. Med. 112; 1117-1120, 1988.

19. Ogawa, K., Shima, N., Oshio, G., Kudo, H., Nakashima, Y., Yamabe, H. and Takeda, T.: Distribution of vitamin B12 R-binder in lung tumors: implications for cell differentiation. Path. Res. Pract. 184; 234241, 1989.

20. Ogawa, K., Ogawa, O., Koshiba, M., Sugiyama, T., Wakatsuki, Y., Kudo, H., Kim, Y. C., Nakashima, Y. and Yamabe, H.: Immunohistochemical localization of vitamin B12 R-binder in salivary gland tumors: implications for cell differentiation. Path. Res. Pract. 186; 751758, 1990.

21. Poulsen, H. E. and Taylor, C. W.: Histological typing of female genital tract tumors. In "International Histological Classification of Tumours", No. 13, World Health Organization, Geneva, 1975.

22. Salm, R. and Cornwall, R.: Mucin production of normal and abnormal endometrium. Arch. Pathol. 73; 30-39, 1962.

23. Sheppard, K., Bradbury, D. A., Davis, J. M. and Ryrie, D. R.: Cobalamin and folate binding proteins in human tumour tissue. J. Clin. Pathol. 37; 1336-1338, 1984.

24. Sorvari, T. E.: Histochemical study of epithelial mucosubstances in endometrial and cervical adenocarcinomas: with reference to normal endometrium and cervical mucosa. Acta Pathol. Microbiol. Scand. 207 (suppl); 1-85, 1969.

25. Sugimori, H., Ookuma, Y. and Iwasaka, T.: Immunohistochemical properties of the endometrial and cervical adenocarcinoma. Acta Obst. Gynaec. Jpn. 38; 22872288, 1986.

26. Wahlström, T., Lindgren, J., Morhonen, M. and Seppala, M.: Distinction between endocervical and endometrial adenocarcinoma with immunoperoxidase staining of carcinoembryonic antigen in routine histological tissue specimens. Lancet 1; 1159-1160, 1979.

27. Wakatsuki, Y., Inada, M., Kudo, H., Ohshio, G., Matsuda, T., Miyake, T. and Kita, T.: Immunological characterization and clinical implication of cobalamin binding protein in human gastric cancer. Cancer Res. 49; 3122-3128, 1989.

28. Walstedt, V. and Gräsbeck, P.: Cobalamin-binding proteins in human urine: identification and quantitation. $J$. Lab. Clin. Med. 106; 439-444, 1985.

29. Waxman, S. and Gilbert, H. S.: Characteristics of a novel serum vitamin B12 binding protein associated with hepatocellular carcinoma. Br. J. Haematol. 27; 229-239, 1974.

30. Yen, Y., Schmiemann, C. and Damjanov, I.: Lectin histochemistry of uterine adenocarcinomas. Arch. Pathol. Lab. Med. 112; 791-793, 1988. 